In die Skriflig 3

\title{
KNELPUNTE TUSSEN CHRISTENE IN SUID-AFRIKA T.O.V. DIE POLITIEKE BETROKKENHEID VAN DIE KERK
}

Dr. J. M. Vorster

In die afgelope twintig jaar het daar in Suid-Afrika twee groot gesprekke tussen „kerke” plaasgevind. Die eerste was in 1961 toe verteenwoordigers van die WRK by Cottesloe 'n gesprek gevoer het met die Nederduits Gereformeerde Kerk in Suid-Afrika (NGKSA) en die Nederduitse Hervormde Kerk van Afrika (NHA). Die tweede was die onlangse konferensie van Protestantse kerke wat deur die World Alliance of Reformed Churches gereël is. In die jare was daar natuurlik ook ander vorme van kontak tussen kerke wat teweeg gebring is deur die Christelike Instituut en die Suid-Afrikaanse Raad van kerke, terwyl bewegings soos die ACB op Potchefstroom, die eertydse UCM en ander ook gepoog het om 'n gesprek tussen christene in Suid-Afrika op te bou ${ }^{1}$ ). Van al hierdie kontakte was die 1961 beraad by Cottesloe en die WARC konferensie in Pretoria (1979) egter die opsienbarendste.

Opmerklik van feitlik al hierdie gesprekke en veral die van Cottesloe en Pretoria, is dat dit nie gebore is uit werklike ekumeniese nood nie, maar uit kommer oor die sosio-politieke situasie in die RSA. Op die gesprekke het dit dus nie gehandel oor die soeke na 'n suiwer belydenis nie, maar oor die kerk se politieke betrokkenheid in 'n sisteem van afsonderlike plurale ontwikkeling en wat alles daarmee saamhang.

Wat verder opmerklik is, is dat daar in al die gesprekke 'n duidelike en diepgaande polarisasie sigbaar is tussen kerke in SuidAfrika oor dié politieke sisteem. Dit is 'n polarisasie wat deur knelpunte a.g.v. duidelike beginselsverskille na vore gebring word. Wat hier volg is ' $n$ poging om daardie knelpunte aan te dui en krities te evalueer. Om dit te doen is dit, myns insiens, nodig om allereers in soverre dit moontlik is die kontoere te skets van die vergestaiting van hierdie polarisasie in die huidige Suid-Afrikaanse kerklike toneel.

\section{KONTOERE VAN 'N KERKLIKE POLARISASIE:}

Soos reeds gesê word hierdie polarisasie nie bepaal soseer deur konfessionele verskille nie, maar deur die onderskeie standpunte oor die Suid-Afrikaanse politieke sisteem en die roeping van die kerk in hierdie opsig. In hierdie verband kan daar, in sy geheel gesien twee pole onderskei word. Die eerste pool staan kritiesafwysend teenoor die sisteem. Dit beteken dat hulle die afsonderlikheidskonsep totaal verwerp en in die verwerping sterk klem lê op die rol wat die kerk hierin moet vervul. Hierdie krities-afwysende pool is hoofsaaklik ook saamgetrek in die Suid-Afrikaanse Raad van Kerke (SARK). Die tweede pool kan beskryf word as 'n kritiesbegeleidende pool wat beteken dat hulle met kritiek tog nog die breë beginsels van ' $n$ afsonderlikheidskonsep handhaaf en terselfdertyd minder klem lê op die politieke betrokkenheid van die kerk. 


\section{In die Skriflig}

Hierdie krities-begeleidende pool is hoofsaaklik saamgetrek in die Afrikaanse kerke.

Op grond van amptelike kerklike uitsprake en memoranda van kerke kan die kontoere van die polarisasie in die huidige kerklike toneel soos volg getrek word. Tot die krities-afwysende pool behoort die drie dogterskerke van die NGKSA tw. die NG-sendingkerk (kleurling), die NG-kerk in Afrika (swart) en die Reformed Church in Africa (Indiër), die Metodiste kerke, Anglikaanse kerke, Lutherse kerke, Presbiteriaanse kerke in al sy groeperinge en die Congregational Church. Hoewel die Rooms-Katolieke kerk nie in die groot gesprekke deelgeneem het nie, kan hy ook by hierdie pool gevoeg word. Hierdie kerklike pool verteenwoordig statisties besien $8,859,500 \mathrm{chris}$ tene $^{2}$. Tot die krities-begeleidende pool behoort die NGKSA (Blankes), die GKSA en die NHA en dit verteenwoordig 1,863,081 christene. Vanweë die betreklike onbekendheid van hulle standpunte word die AGS, die Baptiste kerke, die swart Nederduitse Hervormde Kerk en die Swart separatistegroepe nie by enige van die pole ingesluit nie.

$\mathrm{Bg}$. indeling is natuurlik vloeibaar, omdat baie lidmate van kerke nie noodwendig die amptelike standpunte van die betrokke kerk huldig nie. Tog is dit in breë trekke 'n aanduiding van die polarisasio wat daar tussen christene in Suid-Afrika leef oor die sosio-politieke situasie en die roeping van die kerk in die verband.

'n Ontleding van die amptelike kerklike stukke wat in die kringe van hierdie twee pole aangetref word, sowel as uitsprake van sg. kerkleiers met kerklike sanksie, toon dat daar veral drie knelpunte ten grondslag lê aan die polarisasie.

Dit is onderskeidelik die visie op die kerk, die primêre betekenis van die christelike boodskap en die analise van die sosio-politieke situasie in Suid-Afrika. Hieraan word vervolgens besondere aan. dag gegee.

\section{DIE KERK AS KNELPUNT:}

Die verskille tussen die twee pole oor hulle visie op die kerk handel veral oor twee sake, nl. hulle verskil in siening oor die verhouding tussen kerk en volk en oor die verhouding tussen kerk en samelewing.

\subsection{Kerk en volk:}

Die krities-afwysende pool sien die kerk as 'n universele nuwe monsheid wat alle natuurlike etniese grense oorkoepel en ophef. Hierdie nuwe mensheid is gebou op die versoeningswerk van Christus ${ }^{3}$. Die standpunt word duidelik weerspieël in 'n boodskap wat die SARK in 1969 aan christene in Suid-Afrika gerig het, waarin dit so gestel word: "The Gospel of Jesus Christ declares that God is reconciling us to himself and to each other, and that therefore such barriers as race and nationality have no rightful place in the inclusive brotherhood of Christian disciples" "4. Hierdie selfde standpunt word weer gestel in sy publikasie "Apartheid and the Church" wat in 1972 verskyn het ${ }^{5}$. 
Benewens die feit dat hierdie model 'n ongekwalifiseerde universalisme van die kerk beklemtoon, word dit dan ook verder gesien as 'n illustrasie van die eenheid van die mensheid. Buthelezi ${ }^{8}$ sê dat die kerk die eenheid van die hele mensheid moet illustreer, en daarom kan die kerk nie erkenning verleen aan enige vorm van verdeeldheid wat daar in die mensheid bestaan nie. In die lig van hierdie standpunt word daar dan ook sterk kritiek uitgeoefen teen die ,,kerk" in Suid-Afrika.

Die Reformed Church of Africa sê: ,It has to be admitted that the Church has largely failed in the past to become the new community of reconciliation and peace as an alternative to separation and suspicion" ?.

Die siening van die kerk as 'n universele nuwe mensheid lei dan ook daartoe dat die krities-afwysende pool baie klem lê op sake soos gesamentlike aanbidding, Nagmaalviering en sg. „multirasiale" gemeentes.

'n Evaluasie van hierdie beskouing soos dit in kerklike kringe in Suid-Afrika figureer gee aanleiding tot die volgende kritiese opmerkings. Eerstens is dit opmerklik dat daar in die kringe nog nie 'n objektiewe dieper eksegese gemaak is van Skrifgedeeltes wat betrekking het op die kwessie van volk en nasie nie. Die Presbiterian Bax $^{*}$ het wel onlangs daaraan aandag gegee, maar dit kan nie beskou word as 'n wetenskaplik verantwoordbare studie nie, omdat dit eintlik bedoel is as ' $n$ kritiek teen die rapport van die NGKSA. Dit laat die vraag ontstaan of die siening van die kerk as 'n nuwe alles-oorkoepelende universele mensheid sonder sodanige eksegese nie geformuleer is vanuit bepaalde teologiese voorveronderstellinge, wat op hulle beurt sterk deur die sosialisme beinnloed is nie. Anders gestel: Word die Bybel nie hier bestudeer deur die ideologiese bril van die sosialisme nie.

Tweedens moet daarop gewys word dat die realiteit van etnisiteit by hierdie kerke tog ook praktiese probleme skep, sodat van gesamentlike aanbidding en ,multirasiale" gemeentes prakties nie veel tereg kom nie. Mothupi ${ }^{9}$ sê dat daar van gesamentlike eredienste min in die Metodiste kerk tereg kom, terwyl Bax ${ }^{10}$ die sg. Engelse kerke beskuldig van skynheiligheid, omdat hulle nie dit wat hulle verkondig prakties toepas nie. Soortgelyke stellinge word gemaak deur Ilett " t.o.v. die Anglikaanse kerk, Mpepele ${ }^{12}$ t.o.v. die Presbiteriaanse kerk, Kameeta ${ }^{13}$ t.o.v. die Duits Evangelies Lutherse kerk en Buthelezi ${ }^{14}$ t.o.v. die Evangelies Lutherse kerk. Dit blyk dat hulle in die praktyk ook stuit teen 'n realiteit wat hulle vanuit 'n bepaalde ideologiese hoek nie wil erken nie.

Teenoor hierdie standpunt van die krities-afwysende pool oor die verhouding kerk en volk stel die krities-begeleidende pool 'n ander standpunt. Dit hou in dat die Bybel t.o.v. die eenheid van die kerk wel erkenning verleen aan natuurlike grense. Hieroor het beide die NGKSA en die GKSA rapporte die lig laat sien ${ }^{15}$. Die kerk word wel gesien as 'n universele eenheid, met behoud van volkereverskeidenheid. Volgens hierdie standpunt kan 'n beleid van afsonderlike 
ontwikkeling op sosiale vlak en die stigting van etniese kerke op kerklike vlak eties aanvaar word. Beide moet egter ook beantwoord aan die liefdesgebod.

Hierdie rapporte bevat wel deeglik eksegetiese studie, maar die konsekwensies daarvan word nie altyd ten volle deurgetrek nie. Coetzee het in sy studie oor Volk en Godsvolk in die Nuwe Testament duidelik aangetoon dat die Bybel nie werk met die begrip "ras" soos wat dit vandag in die sosiologie gebruik word nie, maar slegs met die begrip "volk" ${ }^{16}$. Die rapport van die NGKSA stel dit ook so ${ }^{17}$. Ten spyte daarvan word die begrippe "ras" en ,volk" albei in die rapporte baie verwarrend gebruik. Dit gee die indruk dat 'n staatkundige beleid van rasseskeiding gegrond word op Skrifgegewens wat eintlik handel oor volkereverskeidenheid.

By die NGKSA het hierdie inkonsekwente en foutiewe aanwending van Bybelgegewens groot invloed uitgeoefen op sy sendingbeleid. Dit het daartoe gelei dat die sg. dogterskerke gestig is op „rassegrondslag" d.w.s. aparte kerke vir swart, bruin en Indiër naas die bestaande blanke kerk. Dieselfde praktyk word gevind by die NHKA, wat naas die blanke kerk, 'n swart kerk gestig het. Sedert 1961 het die GKSA in 'n mate wegbeweeg van die rassegrondslag en veel meer die Bybelse volkereverskeidenheid as basis gebruik. Dit moet egter erken word dat die rassedenke in die kerk nog steeds leef. Solank die kerke van die krities-begeleidende pool hierdie inkonsekwentheid handhaaf, sal hulle, myns insiens tereg, van rassisme beskuldig word.

'n Verdere punt van kritiek teen die Afrikaanse kerke, is dat hulle in praktyk teenoor die jonger kerke wat deur hulle sendingarbeid tot stand gekom het, te veel 'n houding van kerklike paternalisme handhaaf. T.o.v. die NGKSA sê Buti: „Ons voel tog partykeer dat ons te veel ge-,,bulldoze" word." „Die blanke broeders wil eerder hê ons moet luister, terwyl hulle die praatwerk doen ...." ${ }^{18}$. By die ander twee Afrikaanse kerke kom hierdie praktyk ook nog dikwels voor, hoewel dié jonger kerke veel meer onafhanklik is.

Die ander groot verskilpunt oor die kerk tussen die twee kerklike pole in Suid-Afrika is hulle onderskeie beskouings oor die verhouding kerk en samelewing, waarby dan ook die hele kwessie van politieke betrokkenheid van die kerk inbegrepe is. Hieraan word verder aandag gegee.

\subsection{Kerk en samelewing:}

By die krities-afwysende pool is daar tans twee kategorieë van standpunte oor die verhouding kerk en samelewing. 'n Groot deel van hierdie pool sien die kerk as 'n groot struktuur wat d.m.v. besluite deur sinodes of kongresse of sentrale komitees die „moral opinionmaker" en die instrument van verandering in die samelewing moet wees. Aan die kerklike struktuur word dan ook ' $n$ ' baie wye aksieradius gegee. Die definiëring van die taak van die kerk in die amptelike memorandum van die Swiss Mission of SA voor die WARC-byeenkoms tipeer hierdie gewilde beskouing treffend: Its (the Church - J.M.V.) responsibility is not limited to the 
individual but encompasses the state, the military establishment, the business community and cultural associations" ${ }^{19}$. Dieselfde memorandum sê later (p. 2): "The Church has been given the task of creating a new society in which to live the reconciliation which is in Christ."

Hiermee saam word in hierdie pool dan ook baie klem gelê op konfrontasie met die owerheid deur die kerk. Die kerk moet as 'n magsinstansie op grond van amptelike getalle, die owerheid konfronteer i.v.m. die samelewing. Dit verklaar dan ook die baie verklarings en openbare uitsprake van bv. die SARK en ander kerke in die groep. Die probleem met hierdie beskouing is dat die kerk in 'n sekere mate van sy uniekheid beroof word. Hy word gesien as 'n groot struktuur wat deur 'n klein hoof beheer word. Die individuele gelowige en die plaaslike kerk word in tipies „,kollegealistiese” sin ondergeploeg.

Die tweede kategorie van standpunte in die krities-afwysende pool t.o.v. die verhouding kerk en samelewing is meer radikaal en toon sterk trekke van die nou-gewilde bevrydingsteologie. Hiervolgens word die kerk self gesien as 'n alternatiewe samelewing ${ }^{20}$. Die kerk moet dus nie net die bestaande orde en die owerheid konfronteer met besluite en voorstelle nie, maar hy moet hom teenlééf en opponeer as 'n alternatiewe model van samelewing. Die standpunt word tans baie kritiekloos gehanteer in kerklike kringe in Suid-Afrika. Die vraag is of so 'n standpunt gehandhaaf kan word sonder aanvaarding van die bodem waaruit dit gegroei het, nl. die radikale bevrydingsteologie. Wanneer aanvaar word dat die Bybel die model bied vir 'n utopie; die Koninkryk van God 'n uitsluitlik aardse aangeleentheid is en die opstanding van Christus slegs beteken dat daar 'n nuwe ,wêreld" opgestaan het, dan kan die kerk gesien word as 'n alternatiewe samelewing, wat die antwoord is op die gebroke wêreld. Myns insiens word dus met die aanname van die begrip: „kerk as alternatiewe samelewing” 'n heel nuwe teologiese denkrigting in Suid-Afrika ingevoer.

Die standpunte van die Afrikaanse kerke oor die verhouding kerk en samelewing word nog sterk beheer deur die Gereformeerde tradisie wat gebou is op dit wat Kuyper onder woorde wou bring met instituut en organisme. Dit beteken dat die kerk as instituut 'n baie duidelike begrensing het en nie as sodanig polities betrokke kan raak nie. Maar aan die ander kant word die roeping van die gelowige in die samelewing t.o.v. bv. politiek, ekonomie, onderwys en arbeid sterker beklemtoon. Dit verklaar in 'n groot mate waarom die Afrikaanse kerke minder polities aktief is as die Engelse en swart kerke.

Tog is in die optrede van die Afrikaanse kerke 'n mate van dubbelslagtigheid te bespeur. Op die WARC-byeenkoms het die NGKSA geweier om 'n besluit te steun waarvolgens die owerheid met sekere voorstelle $\mathrm{i} / \mathrm{s}$ konstitusionele veranderinge in Suid-Afrika genader sal word. Die weiering was op grond van die standpunt dat betrokkenheid by staatkundige konstitutsionele veranderinge nie op die terrein van die kerk lê nie. Tog sê die kerk in sy eie rapport voor die kongres dat hy nog altyd intiem betrokke was by die kon. 


\section{In die Skriflig}

stitusionele ontwikkeling in $\mathrm{SA}^{21}$. Nog ' $\mathrm{n}$ voorbeeld van hierdie dubbelslagtigheid kan genoem word. Beide die NGKSA en die GKSA het onlangs versoeke uit die kring van buitelandse kerke, dat met die owerheid onderhandel moet word oor hersiening van die veiligheiswetgewing in SA, geweier met die argument dat dit nie lê op die terrein van die kerk nie. Tog het beide die kerke geen probleem gehad om met die owerheid te onderhandel oor die stelsel van bonusobligasies nie. Hierdie optrede gee die indruk na buite dat die kerke die owerheid nie wil konfronteer oor sake wat betrekking het op die volkerebeleid nie, maar wel bereid is om dit oor ander sake te doen. Die Engelse en swart kerke maak dan die gevolgtrekking dat dié Afrikaanse kerke die volkerebeleid onkrities onder hulle vleuels neem en blind is vir ongeregtighede wat die stelsel kan meebring.

Die tweede knelpunt tussen die twee pole is die verskil in siening oor die primêre betekenis van die christelike boodskap.

\subsection{Die christelike boodskap as knelpunt:}

T.o.v. die aanvaarding van die gesag van die Skrif is die protestantse kerke in Suid-Afrika, ten spyte van baie se verbintenisse met die WRK, nog betreklik behoudend. Dit blyk ook uit die memoranda wat gedien het op die WARC kongres.

Tog heers daar taamlik verskil in siening oor die primêre betekenis van die evangelie vir die mens vandag. Hoewel beide pole in die Suid-Afrikaanse kerklike toneel die botydelike heilskarakter van die Skrif onbevange erken, word die klem tog verskillend gelê. Die krities-afwysende pool lê meer klem op die sosio-politieke implikasies van die heilsboodskap wat dan beteken: „the Gospel is a message addressed to the poor, the broken hearted, the blind, the bruise and the captives" ${ }^{22}$. In hierdie kring word baie sterk gewaarsku teen die siening dat die Bybel slegs te make het met die persoonlike heil en die eis tot persoonlike bekering en geloof. Ngakane van die SARK sê: „Bevryding sluit vir ons alles in: geestelike, psigiese, sosiale, politieke bevryding.... alles. Liberation sê alles" ${ }^{23}$. Daarom word veral in die swart kerke ook stewige aansluiting gevind by die Swart Teologie, omdat dit die evangelieboodskap koppel met die politieke en nasionale strewes van die swartman.

Hierteenoor lê die Afrikaanse kerke meer klem op die implikasies van die evangelie vir die persoonlike geloofsbelewing en uitlewing. Die Bybel word hoofsaaklik verkondig as 'n troos en eis vir die gelowige in sy roepingsvervulling. Hierby kry die toekomende volheid van die heil met die Wederkoms van Christus ook veel meer aandag. Dit het die Afrikaanse kerke al die beskuldiging op die hals gehaal dat hulle spesifiek aan die swartman 'n "pie in the sky" verkondig. Aan die ander kant word die krities-afwysende pool dikwels beskuldig van 'n Social Gospel.

Myns insiens is albei hierdie beklemtoninge erg eensydig en is elkeen besig om die evangelie te verskraal deur valse teenstellinge te handhaaf. Die evangelie verkondig primêr die koms van die Koninkryk van God, wat met die Wederkoms van Christus voltooi 
sal word. Maar dit is nie net toekomsmusiek nie, want, hoewel onvoltooid, is die Koninkryk reeds hier en die eis om die Koninkryk te soek (Matt. 6:33) het ook politieke implikasies vir die gelowige. Christen-wees beteken om verlangend op die Wederkoms te wag, maar ook om sout van die aarde en lig van die wêreld te wees. Daar moet dus gewaak word teen 'n eensydige beklemtoning van die evangelie.

Ten slotte word die derde knelpunt tussen die twee pole kortliks bespreek. Dit is hulle onderskeie sienings van Suid-Afrika.

\section{SUID-AFRIKA AS KNELPUNT:}

Die krities-afwysende pool sien Suid-Afrika as 'n eenheid bestaande uit „South Africans". Die stelling dat die Suid-Afrikaanse samelewing 'n plurale samelewing is, word verwerp. Twee uitsprake druk die gevoel treffend uit. Die UCCSA sê: „South Africa is one nation and its territorial integrity should be maintained" ${ }^{24}$. In lyn daarmee sê die Reformed Church in Africa: „Citizenship of South Africa is the inalienable birthright of all South Africans" ${ }^{25}$. Daarmee saam word enige stelsel wat gebou is op die erkenning van pluralisme of dit wil handhaaf geheel en al afgewys.

Die huidige stelsel van afsonderlike ontwikkeling is dus vir hierdie kerke heeltemal onaanvaarbaar. Buthelezi noem dit „a philosophy of failure" ${ }^{26}$, omdat dit volgens hom 'n sondige verskeurdheid kondoneer en met ' $n$ politieke beleid wil handhaaf. Dieselfde standpunt word amptelike gestel deur die NG-sendingkerk ${ }^{27}$. Ook die nuwe konstitusionele voorstelle betreffende die Kleurlinge en Indiërs word verwerp, omdat dit volgens die kerke dieselfde beginsels ten grondslag het as die hele beleid van afsonderlike ontwikkeling. Veral die NG-sendingkerk en die Reformed Church of Africa het hulle hierteen uitgespreek ${ }^{28}$.

Al hierdie kerke het die standpunt dat die hele sisteem van afsonderlike ontwikkeling in sy geheel verwerp moet word. Dan moet daar langs die weg van 'n nasionale konvensie na 'n nuwe bedeling in Suid-Afrika gesoek word waarin almal gelyke en dieselfde politieke regte het.

Myns insiens word die visie van hierdie kerke op Suid-Afrika as 'n eenheidstaat, soos hulle siening van die kerk as 'n ongekwalifiseerde universele mensheid, bepaal deur 'n bepaalde ideologiesgekleurde vertrekpunt. Vanuit 'n sosialistiese siening op die eenheid van die mensheid wat veral die twintigste eeuse denke beheers, word die realiteite van etniese en kulturele pluralisme in Suid-Afrika ontken. Dit lei daartoe dat hulle 'n eenheid in Suid-Afrika wil forseer en alle etniese gebondenheid en gevoel asook enige staatkundige stelsel wat daarop gebou is as rassisties klassifiseer.

'n Verdere opmerklike aspek van hierdie pool se siening van Suid-Afrika, is sy onkritiese hantering van die neo-Marxistiese maatskappykritiek in sy evaluasie van die Suid-Afrikaanse samelewing. Tiperend hiervan is die beskrywing van die status quo in Suid-Afrika as ' $n$ onderdrukkende struktuur, wat vryheid inperk en wat algeheel verwerp moet word. Alle onreg lê dus by die struktuur. Die „system"” en hulle wat die ,system" geskep het d.w.s. die Afrika- 


\section{In die Skriflig}

ners, word verantwoordelik gehou vir alle ongeregtigheid wat daar in die land mag bestaan. Daarom is hierdie pad ook nie te vinde vir 'n milder afsonderlikheidspolitiek, toegewings en enige vorm van suiwering van die sisteem nie. Daarom word verder ook geen erkenning verleen aan enige positiewe dinge wat deur die beleid van afsonderlike ontwikkeling plaasgevind het nie, en wil hulle hom op geen manier ondersteun nie. Die ,system" moet as geheel omvergewerp word, omdat hy in sy geheel 'n onderdrukkende struktuur sou wees. Suid-Afrika word dus gemeet aan 'n model wat deur die neo-Marxisme van veral Marcuse gebied is.

Veral op hierdie punt word dit duidelik dat die radikale denke van die WRK merkbare invloed in Suid-Afrika het. Agt miljoen christene is tans hiervan die prooi. Die invloed kan hoofsaaklik toegeskryf word aan die SARK aan die eenkant en aan die ander kant die GKN wat openlik besig is om die dogterskerke van die NGKSA met hierdie spyse te voed.

Die krities-begeleidende pool erken op hierdie punt die realiteit van pluralisme in Suid-Afrika en sien ook etiese regverdiging vir ' $n$ beleid van afsonderlike ontwikkeling. In die kringe is daar wel ook, soos getoon op die WARC-kongres, toenemende kritiek teen sekere praktyke en wetgewing wat as onregverdig en uitgedien beskou word. Hieronder kan genoem word sekere aspekte van die veiligheidswetgewing, arbeidwetgewing en onderwys. Die algemene siening by die Afrikaanse kerke is egter dat die stelsel van afsonderlike ontwikkeling nie noodwendig onderdrukkend hoef te wees nie en dat dit die meer aanvaarbare sisteem is vir die behoud van vrede en orde in 'n plurale gemeenskap soos Suid-Afrika.

Die houding van die Afrikaanse kerke teenoor die beleid van afsonderlike ontwikkeling roep egter, myns insiens, ook kritiese vrae op. Die vraag kan gestel word of daar nie nog steeds al te maklik Skrifbeginsels gesoek word om praktiese politiek te verdedig nie? 'n Verdere vraag is of Afrikaanse kerke nie te maklik onverdedigbare aspekte van die beleid uit party-politieke lojaliteit verdedig nie. Enkele voorbeelde kan genoem word. Tot nog toe het die Afrikaanse kerke nie veel aandag geskenk aan onreg wat deur aspekte van bv. trekarbeid, veiligheidswetgewing, instromingsbeheer, ens. ontstaan nie. Die argumente wat hiervoor aangebied is, soos dat dit nie die kerke se taak is nie of dat hierdie verskynsels wêreldwye verskynsels is, is om reeds genoemde redes nie altyd oortuigend nie. Die indruk word gewek dat die Afrikaanse kerke hulle met die beleid in al sy fasette gekompromiteer het. Dit is nodig dat hier nog meer kritiese begeleiding gedoen word.

\section{KONKLUSIE}

T.o.v. die politieke betrokkenheid van die kerk in Suid-Afrika heers daar tans in kerklike kringe dus baie duidelike meningsyorskille. Die WARC-byeenkoms het dit beklemtoon. Hierdie verskille moet nie net beskou word as nuanseverskille of verskille op die oppervlakte, soos deur soveel kerklike media gestel is nie. Dit lê veel dieper as dit. Die stelling kan inderdaad gemaak word dat kerke in Suid-Afrika mekaar eers op grondliggende teologiese punte 
moet vind alvorens daar sprake kan wees van enige vorm van kerklike konsensus oor die politieke betrokkenheid van kerke in SuidAfrika, want dit gaan nie om 'n verdeling op grond van verskil in politieke siening nie, maar inderdaad om Calvinisme vs. Radikalisme. (Lesing gelewer voor die GTV van Pretoria op 4 Junie 1979).

\section{VERWYSINGS}

1. Dit is natuurlik 'n ope vraag of by hierdie byeenkomste werklik gepraat kan word van 'n amptelike gesprek tussen kerke. Vanuit die oogpunt van 'n Gereformeerde kerkbeskouing, waarin die klem meer gele word op die plaaslike kerk en waarin ' $n$ hoër kerklike instituut met sy moderatuur of dagbestuur of sentrale komitee nie as mondstuk van die kerk beskou word nie, is die begrip „,byeenkoms van kerke" soos dit gebruik is by die WARKkongres disputabel. In die verdere uiteensetting van die tema van hierdie studie word egter argumentshalwe aangesluit by die populere termino. logie.

2. Hierdie statistiek is opgestel en verwerk uit gegewens wat gevind is in Meiring, P. 1975 Stemme uit die swart kerk. Kaapstad, Tafelberguitgewers, p. 177.

3. Swiss Mission in SA 1979. The Church and Social responsibility - a memorandum, p. 1.

4. South African Council of Churches 1969 A message of the people of South Africa. In British Council of Churches Violence in Southern Africa a christian Assessment. London SCM Presse, p. 85. Appendix II.

5. Spro-cas 1972. Apartheid and the Church. Johannesburg, Ravan Press, p. 77, Appendix I.

6. Buthelezi, M. 1974. In Meiring a.w. p. 147.

7. Reformed Church in Africa Memorandum: The Church and Social responsibility in South Africa. p. 5.

8. Bax, D. S. Memorandum for the regional consultation of the WARC 1979 on behalf of the Presbyterian Church of Southern Africa, p. 1 e.v.

9. Mothupi, J. In Meiring a.w. p. 47.

10. Bax, D. S. a.w. p. 10.

11. Ilet, L. In Meiring, a.w. p. 86.

12. Mpepele, Z. S. In Meiring, a.w. p. 97.

13. Kameeta, Z. In Meiring, a.w. p. 124.

14. Buthelezi, M. In Meiring, a.w. p. 148.

15. Vgl. NGKSA 1976, Human relations and the South African scene in the light of the Scripture. Kaapstad/Pretoria N.G. Kerk uitgewers, en GKSA 1961, Studie van rasseverhoudinge in die lig van die Skrif. Handelinge van die sinode 1961, p. 51 e.v

16. Coetzee, J. C. 1965, Volk en Godsvolk in die Nuwe Testament. Potchefstroom, Pro Rege.

17. NGKSA, a.w. p. 12.

18. Buti, S. a.w. p. 18.

19. Swiss Mission in SA, 1979, a.w. p. 1.

20. The United Congregational Church of Southern Africa. 1979. Memorandum for consulation on human rights, p. 2 Hierdie stelling is oorgeneem uit besluite van die South African Missiological Society: 1977.

21. NGKSA, a.w. p. 5 . 
22. African Presbyterian Church. Memorandum. Church and social responsibilities in South Africa. p. 1.

23. Ngakane, M. In Meiring a.w. p. 163.

24. The United Congregational Church of South Africa a.w. p. 5.

25. Reformed Church of SA a.w. p. 1.

26. Hierdie stelling het hy gemaak in 'n toespraak voor 'n werkgroep tydens die WARC-kongres.

27. N.G.-sendingkerk, a.w. p. 4.

28. N.G.-sendingkerk, a.w. p. 5; Reformed Church of Africa a.w. p. 2.

29. Bax, D. S. a.w. p. 6. 